\title{
Implicancias del Código Procesal Constitucional peruano: la consagración de un amparo residual y el nuevo escenario para la tutela de los derechos constitucionales laborales
}

\author{
Christian Donayre Montesinos
}

\section{Sobre la tutela de los derechos laborales por medio del amparo en el Perú}

Uno de los principales cambios que trajo consigo la ley 28237, más conocida como el Código Procesal Constitucional, ha sido el de recoger un proceso constitucional de amparo que comúnmente es denominado "residual», ${ }^{1}$ a diferencia del carácter alternativo que ostentaba antes con la ley 23506, Ley de Hábeas Corpus y Amparo, y la ley 25398, que complementaba las disposiciones de la anterior. Aquel carácter alternativo que, antes de la ley 28237, identificaba al amparo condujo a una "ordinarización» de este proceso constitucional. Este fenómeno, al que en su momento también se denominó «amparización", durante el gobierno de Alberto Fujimori, con la flexibilización y la precarización en el empleo a las que conllevaron sus políticas, se hizo patente sobre todo cuando se exigía la tutela de derechos laborales.

Y es que, contrario a lo que suele ocurrir con el amparo en general y los derechos fundamentales de índole laboral en particular, los canales procesales previstos ordinariamente a los cuales recurrir ante, por ejemplo, un despido arbitrario, no fueron seguidos por el común de la gente, sino que, por las supuestas ventajas que conllevaba, ${ }^{2}$ fue más bien el proceso de amparo la

Profesor titular de Derecho Constitucional de la Pontificia Universidad Católica del Perú.

1 Néstor Pedro Sagüés alude al carácter "heroico» del amparo para explicar la naturaleza subsidiaria que ostenta este proceso constitucional en la gran mayoría de ordenamientos jurídicos, a los cuales hoy, con el Código Procesal Constitucional, se suma el nuestro. En ese sentido, véase su trabajo Derecho Procesal Constitucional. Acción de Amparo. Vol. III. Buenos Aires: Astrea, 1988, p. 166.

2 Decimos supuestas ventajas debido a que, si bien en algunos casos el amparo se erigió 
vía más frecuentemente utilizada por aquellas personas que consideraban que se les había amenazado o lesionado algún derecho laboral constitucionalmente protegido, como puede ser la libertad de trabajo, el derecho al trabajo y el derecho a la estabilidad en el trabajo.

En efecto, tal como sostiene un sector de la doctrina, ${ }^{3}$ la derogada ley 23506 contemplaba, en el primer inciso de su artículo seis, una disposición que, de acuerdo con la jurisprudencia sobre la materia, suponía un derecho de opción del cual gozaba el afectado. En virtud de dicho derecho de opción, él podía elegir entre la vía laboral, es decir, el proceso ordinario, o el amparo, esto es, el proceso constitucional. Fue este último el más utilizado, al parecer por su supuesta rapidez, pese a que no cuenta con actividad probatoria, motivo por el cual muchas demandas también fueron desestimadas.

Como bien puso de relieve el supremo intérprete de nuestra Constitución en el caso Eusebio Llanos Huayco (expediente 976-2001-AA/TC), ${ }^{4}$

[...] en nuestro ordenamiento jurídico, el afectado en sus derechos constitucionales laborales no está obligado a acudir previamente a las instancias judiciales ordinarias, y sólo si en ellas no se hubiera obtenido una tutela judicial adecuada, acudir al amparo. En nuestro país, en efecto, el amparo constitucional no es una vía excepcional, residual o extraordinaria, a la cual el justiciable debe recurrir cuando ha agotado todas las vías judiciales idóneas para tutelar los derechos constitucionales.

Ahora bien, frente al nuevo escenario previsto por el Código Procesal Constitucional en el que se pone al amparo en su justo lugar, una interrogante que indudablemente saltará de inmediato será la siguiente: $\mathrm{y}$ ahora a qué vía debo recurrir si se me amenaza o lesiona un derecho laboral constitucionalmente protegido. Será el proceso ordinario si este se presenta, según el texto del

como el remedio frente a diversas violaciones de ciertos derechos laborales, en otros ello no fue así. $Y$ es que, por ejemplo, en la medida en que el proceso de amparo carece de actividad probatoria, toda vez que lo que busca es la tutela urgente de los derechos que caen dentro de su ámbito de protección, el Tribunal Constitucional peruano ha desestimado algunas demandas por considerar que "la pretensión invocada sólo puede ventilarse dentro de un procedimiento provisto de los elementos probatorios necesarios para determinar con exactitud el cumplimiento de todos y cada uno de los requisitos exigidos por la ley; por lo que no habiéndose probado los hechos que se alegan no se puede amparar la presente acción dejándose a salvo el derecho del demandante para hacerlo valer en la vía correspondiente». Esta cita puede apreciarse en su sentencia del caso Augusto Negreiros Valdez (expediente 882-2000-AA/TC), de fecha 25 de julio de 2002 y publicada el 3 de junio de 2003.

3 En este sentido, Blancas Bustamante, Carlos. El despido en el Derecho Laboral peruano. Lima: Ara Editores, 2002, p. 324; ABAD YUPANQUI, Samuel. El Proceso Constitucional de Amparo. Lima: Gaceta Jurídica, 2004, pp. 402-403; entre otros.

4 Sentencia de fecha 13 de marzo de 2003, publicada el 13 de mayo del mismo año. 
segundo inciso del artículo cinco del Código Procesal Constitucional, como la vía igualmente satisfactoria para aquel derecho cuya amenaza o vulneración venimos sosteniendo, cuestión que deberá ser dilucidada en cada caso concreto sobre la base de algunos criterios que desarrollaremos en este texto.

Trataremos, entonces, de brindarle al lector algunas pautas que debiera tomar en consideración si en este contexto lo que pretende alegar es la amenaza o lesión de la libertad de trabajo, el derecho al trabajo o el derecho a la estabilidad laboral (algunos de los derechos fundamentales de índole laboral más frecuentemente invocados en sede constitucional). Para tal efecto, será necesario precisar cada una de las dimensiones que a cada derecho que hemos mencionado le corresponde; así podrá conocerse cuándo, en efecto, están siendo amenazados o vulnerados. Hemos procurado, además, recoger algunos pronunciamientos del Tribunal Constitucional peruano sobre el particular para hacer la explicación un tanto más ilustrativa. ${ }^{5}$ Posteriormente, intentaremos precisar las vías a las cuales, en principio, debiera acudirse para exigir su tutela.

\section{Algunos de los derechos laborales más frecuentemente invocados por los demandantes en un proceso constitucional de amparo: la libertad de trabajo, el derecho al trabajo y el derecho a la estabili- dad en el trabajo}

Usualmente, podemos encontrar, entre los derechos constitucionales laborales más frecuentemente invocados por los demandantes en un proceso de amparo, a la libertad de trabajo, el derecho al trabajo y el derecho a la estabilidad en el trabajo, cuyos alcances los veremos de inmediato.

Cabe precisar que, si bien es cierto que existen otros derechos laborales constitucionalmente protegidos y, por lo tanto, susceptibles de ser tutelados por este proceso constitucional, la intención de este texto no es la de ocuparnos de todos ellos, sino básicamente la de ofrecerle al lector una serie de precisiones en torno a los derechos más frecuentemente invocados en sede constitucional y una mirada al nuevo escenario que, como consecuencia de la entrada en vigor del Código Procesal Constitucional, hoy existe para la protección de los derechos fundamentales de índole laboral.

Sobre la necesidad de tener claros los márgenes que corresponden a cada uno de los derechos que hemos mencionado y su contraste con lo desarrollado por el supremo intérprete de nuestra Constitución al respecto, puede revisarse nuestro trabajo "Libertad de trabajo, derecho al trabajo y derecho a la estabilidad en el trabajo en la jurisprudencia del Tribunal Constitucional peruano». Revista Peruana de Jurisprudencia, año 6, n. ${ }^{\circ}$ 35, enero, 2004, p. 21 y ss., Trujillo. 


\section{Los ámbitos de protección de la libertad de trabajo y las conductas que pueden amenazarla o lesionarla}

$\mathrm{Al}$ interior del Título I de la Constitución peruana de 1993 ha sido recogida la libertad de trabajo. En el inciso 15 del artículo 2, dentro del capítulo primero que lleva por título "Derechos fundamentales de la persona", encontramos una referencia a ella, así como en el artículo 59, en donde se regula el rol económico del Estado.

Básicamente, podemos afirmar que la libertad de trabajo involucra una serie de decisiones que pasamos a reseñar muy brevemente.

\subsection{La decisión de trabajar o no como parte del contenido de la libertad de trabajo y sus implicancias frente al deber de trabajar recogido en la Cons- titución vigente}

En primer lugar, la libertad de trabajo supone la decisión de trabajar o no, la cual, en múltiples oportunidades, ha generado la confrontación de esta dimensión de la libertad de trabajo con el deber de trabajar reconocido también constitucionalmente.

Creemos que el deber de trabajar si bien tiene un reconocimiento jurídico, incluso en el marco constitucional, ${ }^{6}$ las consecuencias de su incumplimiento repercuten tan solo en el ámbito moral o social, mas no en el plano jurídico.7 Es más, en nuestra modesta opinión, el sostener lo contrario bien puede suscitar serias afectaciones a la libertad de la persona. Por ello, aun cuando existen ciertas obligaciones particulares de trabajar reconocidas incluso en los tratados internacionales, ${ }^{8}$ como es el caso del servicio militar obligatorio, ${ }^{9}$ el trabajo penitenciario y las comunes obligaciones cívicas o como puede ser la de colaborar durante los comicios, estas deben interpretarse restrictivamente.

Ahora bien, la perspectiva de la libertad de trabajo que venimos analizando, es decir, aquella posibilidad de decidir si se despliega o no la energía laboral, puede verse afectada por la existencia de trabajos forzosos no previstos, en todo caso, en la Constitución o en la ley o por la de trabajos que no

En este tenor, véase el artículo 22 de la Constitución de 1993.

MARTín VALVERDE, Antonio. "Pleno empleo, derecho al trabajo, deber de trabajar en la Constitución Española». En Derecho del Trabajo y de la Seguridad Social en la Constitución. Madrid: Centro de Estudios Constitucionales, 1980, pp. 194-195.

$8 \quad$ Léase a este respecto el artículo 8, numeral 3, del Pacto Internacional de Derechos Civiles y Políticos, por citar un caso.

9 Hoy en el Perú con la ley 27178 se encuentra vigente más bien un servicio militar voluntario. 
respeten pautas de razonabilidad que buscan evitar restricciones abusivas a esta libertad. ${ }^{10}$

\subsection{La facultad de decidir en qué actividad se despliega la energía laboral como parte del contenido de la libertad de trabajo}

Luego, la libertad de trabajo comprende, a su vez, la facultad de decidir en qué actividad el sujeto va a desplegar su energía laboral, decisión que, por cierto, bien puede relacionarse con la libertad de elección de alguna profesión en específico. Es más, en muchas ocasiones, el inclinarse por el desarollo de una determinada actividad laboral se encuentra íntimamente vinculado con el proyecto de vida del individuo, ${ }^{11}$ por lo que su afectación no solo genera consecuencias que escapan a una mera restricción laboral, sino que, además, implica un obstáculo para el desarrollo de la persona y, como su nombre lo indica, su plan de vida. Por lo dicho entonces, tales restricciones deben estar conformes con el ordenamiento jurídico y ser razonables.

Esta perspectiva de la libertad de trabajo, esto es, aquella que se enmarca dentro de la elección de en qué actividad se encuentra uno dispuesto a depositar su energía, puede ser susceptible de verse conculcada por impedimentos, obstáculos o la exigencia de cumplir con ciertos requisitos irrazonables antes de desarrollar una actividad laboral específica. Así, por ejemplo, en el caso René Arturo Díaz Tavera (expediente 1290-1999-AA/TC), ${ }^{12}$ el demandante solicitó, por medio de un proceso de amparo, que se disponga la emisión del carné que lo reconozca como miembro del Colegio Químico Farmacéutico del Perú (requisito ineludible para laborar como tal en nuestro país), ante la negativa de esta entidad de otorgárselo. En este caso, es de resaltar que, a pesar de que el demandante alegó la violación del

10 Sobre lo que implica este juicio de razonabilidad que debiera efectuarse cuando estamos ante la limitación o restricción del ejercicio de un derecho fundamental, recomendamos revisar CIANCIARDO, Juan. El principio de razonabilidad. Del debido proceso sustantivo al moderno juicio de proporcionalidad. Buenos Aires: Ábaco de Rodolfo Depalma, 2004, p. 61 y ss.

11 Si se quiere abundar sobre lo que involucra el proyecto de vida y las repercusiones de su afectación, recomendamos revisar FERNÁNDEZ SESSAREGO, Carlos. "Daño al proyecto de vida». Derecho PUC, . $^{\circ}$ 50, diciembre, 1996, p. 47 y ss.; id. "El daño al proyecto de vida en una sentencia de la Corte Interamericana de Derechos Humanos». Revista Peruana de Jurisprudencia, año 4, n. ${ }^{\circ}$ 12, febrero, 2002, Trujillo; id. "Daño moral y daño al proyecto de vida». Revista Jurídica del Perú, año LII, n. ${ }^{\circ} 31$, febrero, 2002, p. 43 y ss., Trujillo; id. "Nuevas reflexiones sobre el daño al proyecto de vida» Revista Jurídica del Perú, año LII, n. ${ }^{\circ} 38$, septiembre, 2002, p. 59 y ss., Trujillo; id. "Deslinde conceptual entre "daño a la persona", "daño al proyecto de vida" y "daño moral"». Revista de Derecho Foro Jurídico, año I, n. ${ }^{\circ} 2$, julio, 2003, p. 15 y ss.; entre otros trabajos del mismo autor.

12 Sentencia de fecha de 16 de octubre de 2001, publicada el 18 de junio de 2002. 
derecho al trabajo, el Tribunal Constitucional, creemos nosotros con acierto, enmarcó la conculcación dentro de la libertad de trabajo. El Alto Tribunal dispuso sobre el particular lo siguiente:

La Libertad de Trabajo consiste en la facultad libre de ejercer cualquier tipo de actividad productiva, sin impedimientos constitucionales, ilegales o irrazonables, por parte del Estado o de particulares. Se prohíbe entonces cualquier injerencia que limite o impida esta facultad irrestricta. En consecuencia, el no otorgamiento del carné limita ilegítimamente la libertad de trabajo del recurrente, enunciada en el inciso 15) del artículo $2^{\circ}$ de la Constitución.

A pesar de encontrar decisiones de este tipo, aún son constantes las confusiones conceptuales a las que llegan, por ejemplo, los demandantes al momento de invocar el derecho afectado, sino véase el caso María Magdalena Ventura Casas (expediente 2321-2002-AA/TC), ${ }^{13}$ en donde en una situación en la que se podría haber afectado el derecho al trabajo bajo los términos que explicaremos luego, es decir, como el derecho a acceder a un trabajo específico como consecuencia de haber obtenido el máximo puntaje en un concurso de méritos, se alegaba la libertad de trabajo como la supuestamente conculcada.

\subsection{La libertad de decidir para quién uno está dispuesto a trabajar como parte del contenido de la libertad de trabajo: ¿trabajo por cuenta propia o tra- bajo por cuenta ajena?}

Ahora bien, otra decisión que comporta la libertad de trabajo es para quién uno está dispuesto a trabajar, es decir, si se opta por ser trabajador por cuenta ajena o por cuenta propia. Esta perspectiva de la libertad en comento podría verse conculcada si es que nos encontramos ante una situación en la que un individuo es obligado a desplegar su energía a favor de un tercero en contra de su propia voluntad, esto es, forzado a trabajar por cuenta ajena.

El caso de los trabajadores por cuenta propia es por demás interesante, ya que, en este supuesto, la libertad de trabajo entra a coincidir con la libertad de empresa. Todos los sujetos, como dijimos, son libres de decidir a favor de quién están dispuestos a trabajar, lo cual no obsta para que puedan trabajar también para su propio beneficio, esto es, siendo ellos mismos los titulares de los frutos de su desempeño laboral, de ahí que lo que hacen estos individuos es crear una empresa para dicho fin. Estas circunstancias

13 Sentencia de fecha 5 de diciembre de 2002, publicada el 12 de junio de 2003. 
conllevan, pues, a que la libertad de trabajo de ese sujeto coincida con el desarrollo de las labores de su empresa y, por lo tanto, si se impide u obstaculiza la realización de las actividades productivas de la misma, se podría estar afectando la libertad de trabajo del titular de esa empresa, lo que en rigor, como adelantamos, se entiende como libertad de empresa.

\subsection{La renuncia como manifestación de la libertad de trabajo}

Para terminar con lo que se refiere a la libertad de trabajo, debemos señalar que esta comprende también la decisión, por parte del sujeto, de renunciar a continuar desplegando su actividad laboral. Evidentemente, en este caso nos encontramos ante un supuesto de trabajo por cuenta ajena, pues, en el caso de un trabajo por cuenta propia, uno cesa simplemente de desarrollar la actividad empresarial en ejercicio de esa libertad, claro está con las responsabilidades que ello le genere frente a algunas obligaciones contraídas con anterioridad.

En el supuesto, entonces, de un trabajo por cuenta ajena, la afectación puede producirse como consecuencia de la prohibición impuesta por el empleador a fin de evitar que el sujeto que labora para él renuncie al puesto de trabajo. Esta última afirmación debe ser tomada con cuidado, pues existen casos en los que el empleador ha invertido en el propio trabajador, como, por ejemplo, en la adquisición de nuevos conocimientos y mejor preparación con el objeto del óptimo desempeño de este a favor de su empresa. Resulta que, en este último supuesto, el trabajador debiera continuar laborando para la empresa hasta que culmine el tiempo establecido en el contrato de trabajo o termine de cubrir aquellos costos en que incurrió el empleador en su beneficio; en caso contrario, deberá indemnizarlo.

\subsection{La libertad en el trabajo y su diferencia con la libertad de trabajo}

Ahora bien, cuando un sujeto pone a disposición su actividad laboral en favor de un tercero, ello no supone cesión absoluta de su libertad, sino tan solo de su energía de trabajo en las condiciones pactadas. En consecuencia, el individuo todavía mantiene un margen de su propia libertad que puede verse desplegada aun dentro de la relación laboral y que no debe ser conculcada.

Así, por ejemplo, el sujeto aún es libre de elegir qué opta por consumir dentro del centro de trabajo y como parte de su refrigerio en el horario pactado; así también decide con quiénes entablar una amistad dentro del centro de trabajo; y, a su vez, mantiene su libertad de expresión; entre otros 
derechos. ${ }^{14}$ Por lo tanto, no debe confundirse la libertad de trabajo con la libertad en el trabajo, al ser la segunda ejercitable incluso fuera del escenario laboral.

Una vez que hemos intentado establecer aquí en justos términos lo que supone la libertad de trabajo y la libertad en el trabajo, pasemos entonces ahora a analizar lo que en rigor comprende el derecho al trabajo para, así, precisar también sus distintas perspectivas de protección para evitar incurrir en errores conceptuales al momento de invocar su tutela o efectivamente otorgarla.

\section{Los ámbitos de protección del derecho al trabajo y las conductas que pueden amenazarlo o lesionarlo}

El derecho al trabajo comprende, al igual que la libertad de trabajo, distintas perspectivas de protección que es preciso entrar a definir aquí. Así, en un primer plano, comprende el derecho de acceso al empleo y, en un segundo plano, el de conservar el empleo. El derecho a la ocupación efectiva del puesto de trabajo es considerado por algunos también como parte del derecho al trabajo, tal como veremos luego.

Según lo dispuesto por el Tribunal Constitucional peruano en el caso Sindicato Unitario de Trabajadores de Telefónica del Perú S. A. y FETRATEL (expediente 1124-2001-AA/TC), ${ }^{15}$ el contenido esencial del derecho al trabajo «implica dos aspectos. El de acceder a un puesto de trabajo, por una parte y, por otra, el derecho a no ser despedido sino por causa justa».

\subsection{El derecho de acceso al empleo como parte del contenido del derecho al trabajo: la exigibilidad y eficacia de los derechos económicos, sociales y culturales}

En torno al acceso al empleo es menester distinguir, a su vez, una modalidad general de una particular y específica. El derecho de acceso al empleo desde el punto de vista general, reconocido, por cierto, en el artículo 23 de la Constitución de 1993 vigente, se presenta cuando este es exigido frente

14 Es menester, entonces, distinguir entre aquellos derechos laborales específicos, que son los que tienen su razón de ser u origen en el ámbito de las relaciones laborales, por lo que su ejercicio no es posible fuera de las mismas, de aquellos otros llamados derechos laborales inespecíficos, los cuales no son en estricto laborales, sino más bien generales, pero cuyo ejercicio también es posible dentro de una relación de trabajo. Léase sobre el particular PALOMEQUe LóPEZ, Manuel-Carlos y Manuel ALVAREZ DE LA ROSA. Derecho del Trabajo. 4. ${ }^{a}$ ed. Madrid: Centro de Estudios Ramón Areces, 1996, p. 150 y ss.

15 Sentencia de fecha 11 de julio de 2002, publicada el 11 de setiembre del mismo año. 
al Estado como parte de su obligación de procurar el desarrollo de todos los derechos fundamentales y el bienestar social. Sin embargo, como bien puede deducir el lector, esto puede generar algunos problemas y dificultades que es necesario entrar a reseñar aquí.

Como es de conocimiento general, los derechos laborales se encuentran dentro de lo que se conoce como los derechos económicos, sociales y culturales. La consagración constitucional de estos derechos es producto de la lucha por la reivindicación de los derechos de los trabajadores y existe el compromiso de los poderes públicos para consolidar progresivamente su plena eficacia.

Los derechos económicos, sociales y culturales en general y los laborales en particular cuentan con especiales características, las que, desde ningún punto de vista, deben llevarnos a desconocer su calidad de derechos fundamentales ni tampoco a negar su exigibilidad frente al Estado. Precisamente es en este punto en el que queremos hacer especial incidencia.

Los derechos económicos, sociales y culturales son considerados como derechos de segunda generación en razón de que su aparición dentro del escenario del Estado se da luego de que se hiciera evidente que el reconocimiento de las libertades fundamentales, incluidas las que se conocen como derechos civiles y políticos, era insuficiente. Así pues, estos últimos derechos reconocidos en un principio son denominados derechos de primera generación, mientras que los derechos económicos, sociales y culturales son los llamados de segunda generación. Se trata naturalmente de una constatación histórica, de cómo se dieron los hechos en el transcurrir del tiempo a efectos de lograr su reconocimiento. Esta clasificación nos llevará luego a denominar a una nueva categoría de derechos que involucran facultades y potestades del hombre directamente relacionadas con el desarrollo industrial, tecnológico e informático de la sociedad actual como los derechos de tercera generación, dentro de los cuales encontramos, por ejemplo, el derecho a un medio ambiente adecuado; el derecho de la humanidad a que se respete el patrimonio genético de cada individuo y la dignidad del ser humano, tanto presente como futuro; ${ }^{16}$ entre otros.

Los derechos económicos, sociales y culturales presentan ciertos rasgos que implican, a su vez, una actitud diferente del Estado frente a estos, sin

16 Así lo ha sostenido ANDORNO, Roberto. "La dignidad humana como noción clave en la Declaración de la UNESCO sobre el genoma humano». Revista de Derecho y Genoma Humano, ${ }^{\circ}{ }^{\circ} 14,2001, p .41$ y ss.; sobre este tema en específico, p. 44-45. Nosotros también tuvimos oportunidad de pronunciarnos en este sentido en nuestro trabajo escrito en coautoría con Abraham García Chávarri intitulado "Algunas consideraciones acerca de la clonación con fines reproductivos, sus límites e implicancias jurídicas. A propósito de la dimensión ontológica del ser humano y la libertad de las generaciones futuras». En Normas Legales, t. 341, vol. II, octubre, 2004, p. 3 y ss., Trujillo. 
perjuicio de la exigibilidad que les corresponde por el solo hecho de ser derechos fundamentales. Estos rasgos a los que hacemos referencia serán tratados muy resumidamente en seguida.

El primer rasgo, que debe quedar claramente establecido desde un inicio, es, insistimos, su exigibilidad. ${ }^{17} \mathrm{~A}$ diferencia de ciertas opiniones en la doctrina que consideran que los derechos económicos, sociales y culturales, en la medida en que no pueden materializarse solos, es decir, sin la intervención del Estado, no son en estricto derechos fundamentales, nosotros somos de la opinión de que ello no puede ni debe conllevarnos a efectuar una afirmación de esa naturaleza.

Aquellos argumentos que buscan desestimar el carácter de derecho fundamental de los derechos económicos, sociales y culturales a partir de las dificultades para su exigibilidad frente al Estado no deben perder de vista que estos se encuentran consagrados en el texto constitucional, el cual no es solo una carta política, sino también norma jurídica; por lo tanto, todos los poderes públicos, e incluso los privados, se encuentran directamente vinculados a ella y deben orientar su accionar con miras a lograr consolidar los principios y pautas allí recogidas en la realidad. El carácter normativo de la Constitución les garantiza, entonces, su propia eficacia en la actuación estatal —en tanto poderes constituidos - e, inclusive, en las relaciones entre privados. Esto es lo que Ihering calificó como la «fuerza vinculante bilateral de la norma».

De lo dicho, entonces, bien se puede deducir que tanto el Estado como los particulares ${ }^{18}$ se encuentran obligados a respetar los derechos económicos,

17 Véase ABRAMOVICH, Víctor y Christian COURTIS. "Hacia la exigibilidad de los derechos económicos, sociales y culturales». Contextos. Revista Crítica de Derecho Social, n. ${ }^{\circ} 1$, 1997, p. 3 y ss., Buenos Aires; así Como ABRAMOVICH, Víctor. Los derechos sociales como derechos exigibles. Madrid: Trotta, 2002; entre otros trabajos sobre el particular.

18 Léase respecto de las distintas posiciones existentes en relación con la eficacia de los derechos fundamentales entre particulares, es decir, respecto de la doctrina norteamericana de la State Action, la alemana de la Drittwirkung der Grundechte y aquella otra que pregona a todas luces la eficacia inmediata de los derechos fundamentales en las relaciones entre particulares NARANJO DE LA CRUZ, Rafael. Los límites de los derechos fundamentales en las relaciones entre particulares: la buena fe. Madrid: Boletín Oficial del Estado, Centro de Estudios Políticos y Constitucionales, 2000; BILBAO UBILLOS, Juan María. La eficacia de los derechos fundamentales entre particulares. Análisis de la jurisprudencia del Tribunal Constitucional. Madrid: Boletín Oficial del Estado, Centro de Estudios Políticos y Constitucionales, 1997; BLACK, Charles. "State Action». En Leonard Levy et. al. (eds.). Civil rights and equalitiy. Selections from the Encyclopedia of the American Constitution. Nueva York: Macmillan Publishing Company, 1989; BILBAO UBILLÓS, Juan María. Los derechos fundamentales en la frontera entre lo público y lo privado. La noción de State Action en la jurisprudencia norteamericana. Madrid: Mc Graw-Hill, 1997; GarCía TORRES, Jesús y Antonio Jimenez-BLANCO. Derechos fundamentales y relaciones entre particulares (La Drittwirkung en la jurisprudencia del Tribunal Constitucional). Madrid: Civitas, 1986; VERDA Y BEAMONTE, José de. "El respeto a los 
sociales y culturales y, a su vez, a destinar recursos, dentro de sus posibilidades y del marco constitucional, con el objetivo de lograr su eficacia, como todo derecho fundamental que se precie de serlo.

En segundo lugar, tienen un carácter prestacional, pues involucran necesariamente la actuación del Estado, en el que recae la obligación de crear los mecanismos e la infraestructura necesarios para su ejercicio. ${ }^{19} \mathrm{Su}$ eficacia se encuentra sujeta, entonces, a una actitud prestacional por parte del Estado y no solo a una mera actitud garantista.

Ahora bien, y sin perjuicio de su exigibilidad, no podemos desconocer el carácter programático de los derechos económicos, sociales y culturales. Nos explicamos: en la medida en que el ejercicio de estos derechos involucra una peculiar relación individuo-Estado y en la medida en que este último se encuentra obligado a dirigir su aparato con miras a lograr su eficacia y, para tal efecto entonces, a destinar recursos, el Estado debe realizar un programa de acción hacia ese objetivo. No se trata de que la organización estatal pretenda, con miras a conseguir que todos los ciudadanos ejerzan estos derechos plenamente, quedarse sin recursos para atender otras necesidades básicas del individuo. Por el contrario, debido a que se requiere una actitud prestacional del Estado, este debe realizar un programa de acción que le permita atender los derechos económicos, sociales y culturales sin descuidar otras obligaciones que también le son inherentes y, por lo tanto, exigibles. Esta última característica es la que ha llevado a algunos autores ${ }^{20}$ a llamar a estos derechos los «derechos de desarrollo», precisamente porque será la maquinaria del Estado la que se encargará de lograr su concreción y porque contribuyen, además, a que el individuo desenvuelva sus potencialidades.

En cuarto y último término, y como ha enfatizado algún sector de la doctrina, ${ }^{21}$ los derechos económicos, sociales y culturales contribuyen al ejercicio

derechos fundamentales como límite a la autonomía privada». Actualidad Jurídica, t. 93, agosto, 2001, p. 47 y ss., Lima; CIFUENTES MUÑOz, Eduardo. "La eficacia de los derechos fundamentales entre particulares». Revista Jurídica del Perú, año XLVII, $n .^{\circ} 13$, octubrediciembre, 1997, p. 153 y ss., Lima; GARCíA CHÁVARRI, Abraham. "Apuntes sobre la eficacia de los derechos fundamentales entre particulares». En Normas Legales, t. 324, mayo, 2003, p. 11 y ss., Trujillo; entre otras interesantes investigaciones sobre la materia.

19 Lo señalado no supone desconocer que, incluso en el caso de los derechos civiles y políticos, de los cuales se predicaba una actitud abstencionista por parte del Estado, este último ostenta una actitud también positiva en tanto está obligado a garantizar su libre ejercicio, para lo cual debe, a su vez, destinar recursos con miras a consolidar, por ejemplo, una judicatura autónoma, seguridad jurídica, entre otros.

20 Véase CASTRO CID, Benito de. Los derechos económicos, sociales y culturales. Análisis a la luz de la teoría general de los derechos humanos. León: Universidad de León, Secretariado de Publicaciones, 1993, p. 172 y ss.

21 Así, por ejemplo, CASCAJO, José Luis. "La tutela constitucional de los Derechos Sociales». Cuadernos y Debates, n.o 5, 1988, p. 439 y ss., Madrid. 
de otros derechos fundamentales. Esto último requiere una explicación: no tuvo que pasar mucho tiempo para que la población se percatase de que el reconocimiento de las libertades civiles y políticas no garantizaba necesariamente su ejercicio; ¿de qué servía, por ejemplo, que se reconozca a los individuos el derecho de sufragio si se excluía a su vez del ejercicio de este derecho a los analfabetos y el Estado no implantaba políticas educativas con miras a revertir esta deficiencia?. El derecho a la educación es justamente uno de aquellos derechos que se ubican dentro de los llamados derechos económicos, sociales y culturales.

La perspectiva, entonces, del derecho al trabajo como acceso al empleo en su modalidad general encuentra algunas dificultades para que su tutela sea invocada a nivel judicial, toda vez que se encuentra supeditada al desarrollo económico de cada país y a los recursos con que se disponga para tal efecto. Por ello, para los jueces es sumamente complejo decidir cuándo se les presenta un caso de esta naturaleza. ${ }^{22}$

Empero, como se dijo líneas atrás, si bien se trata de un derecho programático, el Estado se encuentra obligado a crear la infraestructura y los

22 Léase a este respecto ESPINOSA-SALDAÑA BARRERA, Eloy. "Apuntes sobre la protección jurisdiccional de los derechos sociales prevista en el ordenamiento jurídico español». Revista Jurídica del Perú, n. ${ }^{\circ}$ 15, abril-junio, 1998; Gonzáles MORENo, Beatriz. El Estado social: naturaleza jurídica y estructura de los derechos sociales. Madrid: Civitas, 2002.

Necesario es señalar qué posiciones en la doctrina vienen reconociendo la efectividad de un mecanismo procesal cuya naturaleza ameritaría ser abordada en un trabajo posterior, pero que, sin duda, viene adquiriendo cada vez más aceptación como medio para hacer frente a la inactividad del legislador, sobre todo en lo que se refiere a la regulación de los denominados derechos económicos, sociales y culturales; asi, se facilita su ejercicio en favor de los ciudadanos. La herramienta a la que hacemos alusión es la de la inconstitucionalidad por omisión.

Como dijimos, este no es el espacio para desarrollar ampliamente esta figura; no obstante, si se quiere investigar más sobre el particular bien puede revisarse FERNÁNDEZ SEGADO, Francisco. "La inconstitucionalidad por omisión: ¿cauce de tutela de los derechos de naturaleza socioeconómica?». En Víctor Bazán (coord.). Inconstitucionalidad por omisión. Santa Fe de Bogotá: Temis, 1997, pp. 7 y ss; también en Themis. Revista de Derecho, 2. ${ }^{a}$ Época, n. 31, 1995, p. 153 y ss; del mismo autor también recomendamos "La dinamización de los mecanismos de garantía de los derechos y de los intereses difusos en el Estado social». Boletín Mexicano de Derecho Comparado, nueva Serie, año XXVII, n. ${ }^{\circ}$ 83, mayo-agosto, 1995, p. 563 y ss., México; y "Los nuevos desafíos para la protección jurisdiccional de los derechos». En La Justicia Constitucional a finales del siglo XX. Revista del Instituto de Ciencias Políticas y Derecho Constitucional. Huancayo: Palestra Editores, 1998, p. 53 y ss.; BAZÁN, Víctor. "Omisiones inconstitucionales y justiciabilidad de los derechos». Revista Jurídica del Perú, año LI, n.․25, agosto, 2001, p. 1 y ss., Trujillo; GÓmez PUENTE, Marcos. La inactividad del legislador: una realidad susceptible de control. Monografía, Ciencias Jurídicas. Madrid: McGraw-Hill, 1997, p. 39 y ss.; CARPIO MARCOS, Edgar y Gerardo ETO CRUZ. El Control de las omisiones inconstitucionales e ilegales en el Derecho Comparado. (Reflexiones a propósito del caso peruano). México: Fundap, 2004, p. 91 y ss.; entre otros textos. 
mecanismos necesarios para lograr su progresiva consolidación; finalmente, es la Constitución, en tanto norma, la que así se lo manda. Dentro de dicha infraestructura se encuentra la legislación que facilite el acceso al empleo, así como su debida protección. Es aquí donde los jueces podrán entrar a evaluar si la referida normatividad respeta el contenido esencial ${ }^{23}$ de este tipo de derechos, salvo mejor parecer.

Es, pues, recurrente en las decisiones del Tribunal Constitucional peruano, dadas las dificultades para otorgar la tutela particular de este derecho en su modalidad general, la presencia de argumentos como "ha visto éste como un deber y un derecho, base del bienestar social y medio de realización de la persona (artículo $22^{\circ}$ ) y, además como un objetivo de atención prioritaria del Estado (artículo $23^{\circ}$ )», es decir, la obligación del Estado de satisfacer este derecho, pero no a título particular. En este último sentido fue el pronunciamiento de nuestro supremo intérprete de la Constitución en el caso José Luis Tuesta Reátegui y otros (expediente 731-99$\mathrm{AA} / \mathrm{TC}){ }^{24}$

El Tribunal Constitucional peruano, en el caso Sindicato Unitario de Trabajadores de Telefónica del Perú S.A. y FETRATEL (expediente 11242001-AA/TC), ${ }^{25}$ señaló que el derecho al trabajo «supone la adopción por parte del Estado de una política orientada a que la población acceda a un puesto de trabajo, si bien hay que precisar que la satisfacción de este aspecto de este derecho constitucional implica un desarrollo progresivo y según las posibilidades del Estado».

No sucede lo mismo cuando estamos frente al acceso al empleo, pero en su perspectiva específica. Esta se presenta cuando, por ejemplo, el trabajador ha postulado a un puesto de trabajo, sea por concurso público o interno, y logra el mayor puntaje exigido. En ese caso, es evidente que el trabajador tendrá derecho a acceder a ese puesto de trabajo, ya que ha demostrado sus habilidades para ello y ha cumplido con los requerimientos planteados para tal efecto.

Un supuesto como al que hacemos referencia es el que se presentó en el caso Hidalgo Vicente Salazar Montenegro (expediente 576-2001-AA/TC), ${ }^{26}$ en el que el accionante exige se deje sin efecto una resolución rectoral por

23 Sobre el contenido esencial de los derechos fundamentales y las teorías existentes al respecto, véase, entre otros, GAVARA DE CARA, Juan Carlos. Derechos fundamentales y desarrollo legislativo. La garantía del contenido esencial de los derechos fundamentales en la Ley Fundamental de Bonn. Madrid: Centro de Estudios Constitucionales, 1994.

24 Sentencia de fecha 5 de mayo de 2000, publicada el 26 de octubre del mismo año.

25 Sentencia de fecha 11 de julio de 2002, publicada el 11 de setiembre del mismo año.

26 Sentencia de fecha 10 de julio de 2002, publicada el 25 de noviembre del mismo año. 
medio de la cual se nombró docente a un sujeto que no había logrado el más alto puntaje en el concurso de méritos y oposición, mientras que sí había sido obtenido por el demandante. En este caso, con acierto, el Tribunal Constitucional, al momento de delimitar la controversia, señala que esta radica en el derecho a acceder en igualdad de condiciones a los cargos y empleos públicos, para lo que cita incluso los artículos 1 y 3 del Convenio 111 de la Organización Internacional del Trabajo (OIT). Así, en este supuesto declara fundada la demanda por considerar que la decisión de la Comisión Central del Concurso de Docentes había sido arbitraria.

Por lo expuesto se afirma que la perspectiva general del derecho al trabajo en lo que al acceso al empleo se refiere goza de eficacia diferida, ${ }^{27}$ mientras que, en su perspectiva más bien específica, cuenta con eficacia inmediata.

\subsection{El derecho a conservar el empleo y a la ocupación efectiva del puesto de trabajo como parte del contenido del derecho al trabajo}

Ahora bien, la otra perspectiva del derecho al trabajo que venimos comentando, y que ya adelantamos, viene a ser la de conservar el empleo que ya se ha obtenido. Según se dice, esta coincidiría parcialmente con lo que en doctrina se ha reconocido como la prohibición del despido arbitrario. ${ }^{28}$ Esta coincidencia parcial se debería a que el derecho al trabajo no solo comprendería el derecho a no ser despedido arbitrariamente, sino tampoco por cualquier otra causal no surgida por voluntad del trabajador. Así, y dentro de esta última posibilidad, podemos encontrar, por ejemplo, la jubilación obligatoria. Sobre el particular, según jurisprudencia constitucional española, ${ }^{29}$ no podría sostenerse que tal jubilación viola el derecho al trabajo, si lo que se busca con dicha medida es que los jóvenes accedan a puestos de trabajo.

Un supuesto distinto del antes citado se presentó en el caso José Leoncio Matos Sotelo (expediente 1485-2001-A/TC). ${ }^{30}$ En esta oportunidad, el trabajador, que se desempeñaba como docente universitario, había adquirido el derecho a la jubilación, lo cual supone, a diferencia de la jubilación obligatoria, que se retirará de la actividad laboral, en este caso de la docencia, cuando

27 NEVES MuIICA, Javier. «Libertad de trabajo, derecho al trabajo y derecho de estabilidad en el trabajo.». En Derecho \& Sociedad, n.․ 17, diciembre, 2001, p. 24 y ss., Lima; aunque en dicha publicación no se consignó por completo el trabajo citado, sino seriamente recortado. Por ello, agradecemos, mediante estas líneas al profesor Javier Neves por habernos facilitado el acceso al texto original.

28 Ib., loc. cit.

29 Véase la sentencia del Tribunal Constitucional español 22/1981, de 2 de julio.

30 Sentencia de fecha 11 de setiembre de 2002, publicada el 3 de junio de 2003. 
él así lo decida, sea porque no puede o porque no desea continuar trabajando. No obstante ello, el demandante había sido pasado a la jubilación por parte de la demandada por el solo hecho de haber cumplido los setenta años de edad. El Tribunal Constitucional peruano declaró fundada la demanda, entre otras razones, porque

[...] habiéndose acreditado en autos la decisión de cesar al demandante, se han vulnerado sus derechos constitucionales relativos al trabajo y a la protección adecuada contra el despido arbitrario, ya que por razones de edad se estaría privando a un docente de ejercer la cátedra universitaria, cuando es evidente que el sólo hecho de llegar a una edad determinada no disminuye necesariamente las aptitudes que se requieren para el ejercicio de las labores académicas, de funciones administrativas o de alta dirección, que por ley le corresponde en el ámbito de sus responsabilidades.

Esta perspectiva del derecho al trabajo está, pues, relacionada con el despido arbitrario y guarda, entonces, relación con lo que conocemos como el derecho a la estabilidad en el trabajo, derecho que abordaremos posteriormente.

Necesario es anotar también que el derecho al trabajo comprende, además de los dos sentidos reseñados (es decir, el de acceso al trabajo en su modalidad general y específica y el de conservar el empleo), el derecho a la ocupación efectiva del puesto de trabajo. Esto último requiere una explicación: el realizar un trabajo supone un medio por el cual el individuo no solo logra obtener un sustento económico, sino también, como dijimos, consigue desarrollar su persona, su propio profesionalismo o, como ya indicamos, su proyecto de vida. Lo señalado adquiere singular relevancia, además, si constatamos que, para efectos del ascenso o promoción al interior de la institución o empresa en la cual se trabaja, los méritos obtenidos en el desarrollo de las labores constituyen un elemento gravitante.

Por lo expuesto entonces, es sumamente importante reconocer también como digno de tutela la ocupación efectiva, esto es, el desarrollo de la prestación laboral de forma ordinaria.

Según algún sector de la doctrina, este derecho puede considerarse como una tercera perspectiva del derecho al trabajo, además del derecho de acceso y el de conservación del empleo. ${ }^{31}$ Sin embargo, se ha dicho también que es posible subsumir esta perspectiva dentro de la de conservación del empleo, ya que, según se ha afirmado en precedentes jurisprudenciales, el no utilizar al trabajador o emplearlo en tareas fútiles que no contribuyen a su desarrollo, o que no se condicen con las labores para las cuales fue contratado

31 Léase sobre el particular GORELLI HERNÁNDEZ, Juan. El cumplimiento específico de la readmisión obligatoria. Madrid: Civitas, 1995, p. 35 y ss. 
y se encuentra calificado, equivaldría a un despido arbitrario. En todo caso, lo relevante es rescatar que el derecho al trabajo no se agota en el derecho de acceso al empleo ni en el de conservarlo, sino que también comprende la ocupación efectiva del mismo.

Sobre este último punto encontramos pronunciamientos de nuestro Tribunal Constitucional, sobre todo en lo que al personal militar y policial se refiere. $\mathrm{Y}$ es que, como se sabe, tanto los militares como los policías son susceptibles de ser desplazados a una situación de disponibilidad. En este caso, no se encuentran separados de la institución en la cual trabajan, sino solo trasladados a una situación transitoria en la que se encuentran apartados de la situación de actividad, pero pueden volver a ella desparecidos los motivos que originaron su separación del servicio activo.

Durante el lapso de tiempo que dura esta medida, no pueden ejercer labor alguna vinculada con su carrera. Dadas las consecuencias de semejante situación, resulta sumamente relevante y necesario establecer algún plazo específico de conclusión para evitar una afectación irrazonable y desproporcional del derecho al trabajo al que puede conducirnos no contar con él.

Así, en el caso Hernán Vivanco Paz (expediente 246-2001-AA/TC), ${ }^{32}$ el Alto Tribunal reconoce la afectación del derecho al trabajo, debido a que un sujeto de la Policía nacional se encontraba en situación de disponibilidad más allá del plazo establecido en la legislación correspondiente.

De lo dicho hasta aquí podemos afirmar que el derecho de acceso al empleo a nivel específico (no general, pues ya hemos visto los problemas a los que nos enfrentamos en este ámbito, en donde el papel del Estado y los recursos con que se cuenta son elementos que no pueden dejarse de lado para su plena eficacia, lo que no impide, insistimos, su respeto y exigibilidad en cierta medida para lograr progresivamente su consolidación) es un derecho de eficacia inmediata, al igual que el de conservación del puesto de trabajo. Por otro lado, también la ocupación efectiva del empleo, reconocida como parte del derecho al trabajo, cuenta con eficacia inmediata.

A continuación, abordaremos el otro derecho que había quedado pendiente según las líneas precedentes: el derecho a la estabilidad en el trabajo.

\section{El derecho a la estabilidad en el trabajo: breve referencia a sus alcances}

El derecho a la estabilidad laboral comprende dos aspectos, uno referido a la estabilidad de entrada y otro a la estabilidad de salida. La primera alude a la preferencia por la contratación de duración indefinida sobre la definida, mientras que la segunda a la proscripción del despido arbitrario.

32 Sentencia de fecha 14 de junio de 2001 y publicada el 18 de junio de 2002. 
En lo que se refiere al primer aspecto aquí señalado del derecho a la estabilidad laboral, es decir, el de favorecer los contratos de duración indeterminada, frente a aquellos llamados contratos temporales, debe tenerse en cuenta que la celebración de estos últimos debiera darse solo cuando se trate de actividades de esa naturaleza. Así, por ejemplo, en el caso José Luis Tuesta Reátegui y otros (expediente 731-1999-AA/TC), ${ }^{33}$ el Tribunal Constitucional peruano, ante un supuesto de despido arbitrario, estimó que los codemandantes realizaban labores de naturaleza permanente, a pesar de que pareciera que habían suscrito contratos temporales de trabajo, por lo que, en virtud del principio de primacía de la realidad, no podían ser cesados ni destituidos sino por las causas previstas en el capítulo $\mathrm{V}$ del decreto legislativo 276, con sujeción al procedimiento en él establecido.

En este caso, claramente el supremo intérprete de nuestra Constitución ha optado no solo por la estabilidad de entrada, toda vez que, dada la naturaleza de las labores que realizaban los accionantes, reconoció que sus contratos de trabajo no eran temporales, sino también por la estabilidad de salida, ya que le exige, finalmente, al demandado que siga el procedimiento previsto para proceder al despido en esos supuestos.

En similar sentido se pronunció el Tribunal Constitucional peruano en el caso Maruja Miriam Montoya Mestanza (expediente 1140-2000-AA/TC). ${ }^{34}$ Allí sostuvo, pues, que

[...] la demandante desempeñó una labor de naturaleza permanente, que se prolongó por más de 8 años, por ello no resiste el menor análisis sostener que una labor que ha tenido tan extenso periodo de duración pueda considerarse razonablemente como «temporal», pues la temporalidad significa lo circunstancial, lo fugaz o perentorio en el tiempo; por el contrario, ese periodo tan dilatado demuestra la naturaleza permanente de la labor desarrollada por la demandante.

Declaró, entonces, fundada la demanda, como quiera que el demandado no había seguido el procedimiento previsto para tales supuestos.

Ahora bien, la estabilidad de salida tiene, pues, en nuestro país, sus problemas particulares y será abordada a continuación con más detalle. Y es que es respecto de la estabilidad de salida en en que el escenario peruano no se muestra muy garantista. Esto último ocurre muy a despecho de algunos autores que afirman, en relación con la actual fórmula peruana, en la que la Constitución ha habilitado al legislador para que sea este quien

Sentencia de fecha 5 de mayo de 2000, publicada el 26 de octubre del mismo año.

34 Sentencia de fecha 5 de agosto de 2002, publicada el 6 de mayo de 2003. 
determine la debida protección frente al despido arbitrario, ${ }^{35}$ el cual opta por la indemnización para la gran mayoría de casos, lo siguiente: «Si algún mérito tiene el nuevo texto es su flexibilidad, ya que permite que el legislador adopte, dentro de las cambiantes exigencias de una sociedad en constante mutación, las reglas que mejor reflejen las necesidades de un momento dado". ${ }^{36}$

Según lo sostenido por el Tribunal Constitucional peruano en el caso Eusebio Llanos Huayco (expediente 976-2001-AA/TC), ${ }^{37}$ la indemnización prevista como protección «reparadora» contra el despido arbitrario

[...] es compatible con los principios y valores constitucionales en aquellos casos en los que, o bien el trabajador, una vez fue despedido arbitrariamente, cobra la indemnización correspondiente o, en su defecto, inicia una acción judicial ordinaria con el objeto de que se califique el despido como injustificado, con el propósito de exigir del empleador el pago compulsivo de la referida indemnización.

\section{Nosotros coincidimos más bien con quienes sostienen que}

[...] la exigencia de una causa deja de tener efectividad si ante su incumplimiento no le sigue, como consecuencia lógica, el reingreso del trabajador en su puesto de trabajo. De lo contrario, será fácilmente soslayable pues en un sistema de despido sin causa indemnizado, siempre es posible la extinción, reduciéndose todo a un simple problema de coste económico. ${ }^{38}$

Ahora bien, como se sabe, la conducta que afecta el derecho a la estabilidad en el trabajo y que ha sido en múltiples ocasiones cuestionada por

35 Así, el artículo 27 de la Constitución de 1993 señala: "La ley otorga al trabajador adecuada protección contra el despido arbitrario».

36 Véase PASCO COSMÓPOLIS, Mario. «El trabajo en la Constitución». Ius et Veritas, año IV, n.․ 7, p. 31 .

El profesor Pasco alude, en la cita que figura en el texto, a la flexibilidad como una de las virtudes del actual texto constitucional. Sin embargo, necesario es señalar que esa flexibilidad también ha generado graves consecuencias en materia de protección de los derechos laborales de los trabajadores, sobre todo ante una situación de despido arbitrario, frente al cual, en la gran mayoría de casos, no queda otro remedio que la indemnización. Entre los críticos de la flexibilización laboral puede revisarse CAMPANA ZEGARRA, David y Herbert PRELLE MAYURI. "La reforma de la contratación laboral durante los noventa: ¿flexibilidad o precarización?». En Estudios sobre flexibilidad en el Perú. Documento de trabajo, n.o 124. Lima: OIT, 2000, p. 51 y ss; de igual forma VILLAVICENCIO Ríos, Alfredo. "La flexibilidad y los mecanismos de subcontratación laboral: el caso de la intermediación». En Estudios sobre flexibilidad en el Perú. Op. cit., p. 81 y ss; entre otros.

37 Sentencia de fecha 13 de marzo de 2003, publicada el 13 de mayo del mismo año.

38 GORELLI HERNÁNDEZ, Juan. Op. cit., p. 37 y ss. 
medio del proceso de amparo es el despido. Necesario es señalar, sin embargo, que no cualquier despido resulta lesivo de un derecho constitucional. Evidentemente, existen oportunidades en las que despedir a un trabajador resulta plenamente justificado y se da de conformidad con el marco jurídico, $y$, en consecuencia, la demanda que se interponga para exigir la tutela de aquel derecho que se considera vulnerado será desestimada. Así, el Tribunal Constitucional peruano, en el tantas veces aquí citado caso Eusebio Llanos Huayco (expediente 976-2001-AA/TC), ${ }^{39}$ ha entrado a precisar los diferentes tipos de despido que pueden resultar lesivos al derecho a la estabilidad en el trabajo y demás derechos constitucionalmente protegidos. ${ }^{40}$

En ese orden de ideas, un despido será nulo cuando

- se despide al trabajador por su mera condición de afiliado a un sindicato o por su participación en actividades sindicales;

- se despide al trabajador por su mera condición de representante o candidato de los trabajadores (o por haber actuado en esa condición);

- se despide al trabajador por razones de discriminación derivados de su sexo, raza, religión, opinión política, etc.;

- se despide a la trabajadora por su estado de embarazo (siempre que se produzca en cualquier momento del periodo de gestación o dentro de los noventa días posteriores al parto);

- se despide al trabajador por razones de ser portador de sida; y

- se despide al trabajador por razones de discapacidad.

Por otro lado, estaremos ante un despido incausado cuando se despide al trabajador, ya sea de manera verbal o mediante comunicación escrita, sin expresarle causa alguna derivada de la conducta o la labor que la justifique.

El despido será fraudulento cuando se despide al trabajador con ánimo perverso y auspiciado por el engaño; por consiguiente, de forma contraria a la verdad y la rectitud de las relaciones laborales. Este tipo de despido se presentará pese a que se cumpla con la imputación de una causal y los cánones procedimentales. Esto último ocurre cuando se le imputan al trabajador hechos notoriamente inexistentes, falsos o imaginarios.

39 Sentencia de fecha 13 de marzo de 2003, publicada el 13 de mayo del mismo año.

40 Algunos autores nacionales han manifestado que la ruptura del vínculo laboral de forma arbitraria trae como consecuencia no solo la violación del derecho del trabajador de conservar el empleo, sino también de otros derechos que exigen semejante protección por parte del ordenamiento jurídico, como es el caso del derecho al honor, a realizar legítimamente actividades sindicales, a la dignidad, entre otros. Léase, sobre el particular, ARCE ORTIz, Elmer. La nulidad del despido lesivo de derechos constitucionales. Lima: Pontificia Universidad Católica del Perú, 1999, p. 108 y ss. 
Cuando se le atribuye al trabajador una falta no prevista legalmente, contraviniendo de esa forma el principio de tipicidad, también se tratará de un despido fraudulento. Eso fue lo que sucedió en casos como el Larry Gómez Sandoval y otros (expediente 150-2000-AA/TC), ${ }^{41}$ el Rose Marie Ríos Vivanco (expediente 555-99-AA/TC) ${ }^{42}$ entre otros. En el primero de los casos mencionados, el Tribunal Constitucional peruano, bajo argumentos que antes ya había consignado en líneas generales en el segundo, sostuvo que,

[...] conforme al artículo 2o, inciso 24) literal «d» de la Constitución Política del Estado, el principio de tipicidad impone que los hechos (actos u omisiones) tipificados como infracciones punibles deben ser establecidos en forma expresa e inequívoca, lo cual no se ha cumplido, conforme se advierte del texto de la carta de imputación de cargos, mediante la cual la demandada atribuye a los demandantes la comisión de falta grave. En efecto, la falta imputada carece de tipicidad, pues, en el caso concreto, las cartas de imputación que se les atribuye a los demandantes por supuesta falta grave de «injuria y falta de la palabra escrita» en agravio de la institución y de sus directivos se limita simplemente a citar la norma legal que considera pertinente, sin preocuparle en absoluto establecer la relación de causalidad entre las características del tipo normativo con la conducta supuestamente infractora, máxime si la supuesta falta grave de injuria y faltamiento de palabra, representaba la publicación en el diario La República, de fojas setenta y uno de autos, con el título "Despedidos reclaman pago de sus sueldos al Banco de la Nación», no acreditándose en autos que los demandantes hayan sido los que contrataron dicho aviso periodístico.

Cuando la extinción de la relación laboral se da con vicio de voluntad, como en el caso Elba Graciela Rojas Huamán (expediente 628-2001-AA/ TC) ${ }^{43}$ o mediante la «fabricación de pruebas», también estaremos ante un despido fraudulento.

En efecto, en el caso Elba Graciela Rojas Huamán, que hemos mencionado, el Tribunal Constitucional peruano señaló:

Los hechos descritos en la demanda, llevados a cabo para dar cumplimiento a una disposición de la Oficina Principal de Telefónica del Perú S. A. A., con el mecanismo de trasladar a la recurrente en horas de la noche a una localidad distinta a la de su centro de trabajo habitual, contrastan con cualquier presunción de que el propio

\footnotetext{
41 Sentencia de fecha 12 de julio de 2000, publicada el 16 de diciembre del mismo año.

42 Sentencia de fecha 4 de noviembre de 1999, publicada el 13 de febrero de 2000.

43 Sentencia de fecha 10 de julio de 2002, publicada el 17 de setiembre del mismo año.
} 
trabajador, haya sido quien voluntariamente optó por extinguir su vínculo laboral. Por el contrario, aparece una declaración de voluntad cuyo instrumento es presentado en la mesa del funcionario indicado, pero bajo un cargo de recepción, que en este caso no existe, como tampoco aparece en dicha carta el lugar o ciudad donde se giró, actos éstos que ponen de manifiesto la ventaja numérica y funcional con que ha actuado la empresa demandada para la obtención de su propósito.

De presentarse, entonces, alguno de los supuestos antes descritos estaremos, según el criterio del Tribunal Constitucional peruano, ante un despido susceptible de ser cuestionado por medio de un amparo. En cambio, en el caso de que se trate de un despido injustificado, es decir, aquel en el cual se despide al trabajador invocando alguna de las causas que permitirían tal accionar, pero no se acredita o prueba de forma fehaciente, debiera acudirse más bien al proceso ordinario, toda vez que, como se indicó anteriormente, el proceso constitucional de amparo carece de actividad probatoria.

Ahora bien, lo poco garantista que, en nuestra opinión, se muestra el escenario peruano para la tutela del derecho a la estabilidad laboral en algunos casos, va a tener serias implicancias en lo que a la utilización del amparo se refiere, sobre todo frente al carácter residual que quiere atribuírsele actualmente a este proceso constitucional. Veamos entonces con detalle el sustento de esta nuestra última afirmación y cuáles serían las vías a las cuales ahora, en principio, debiera acudirse para exigir la tutela de los derechos constitucionalmente protegidos de índole laboral en general.

\section{III. ¿A qué proceso debe ahora acudirse para exigir la tutela de la libertad de trabajo, el derecho al trabajo y el derecho a la estabili- dad en el empleo?}

Como señalamos al inicio de este trabajo, uno de los principales cambios que ha traído consigo la entrada en vigencia del Código Procesal Constitucional peruano ha sido el de circunscribir el proceso de amparo a un carácter residual, valga decir, ha pasado a ser la última vía a la cual, en principio, debiera acudirse para exigir la protección de los derechos fundamentales que caen dentro de su ámbito de tutela. Y es que la ley 28237 ha previsto, en el inciso dos del artículo cinco, como causal de improcedencia de los procesos constitucionales de la libertad (como es el caso del hábeas corpus, el amparo, el habeas data y, mientras la Constitución así lo prevea, el proceso de cumplimiento), la existencia de vías específicas, igualmente satisfactorias, para la protección del derecho constitucional amenazado o vulnerado, causal que no resulta aplicable al proceso de hábeas corpus, pues, como 
señalamos en anterior ocasión, ${ }^{44}$ se parte de la premisa de que no existe otra vía específica igualmente satisfactoria para los derechos que este proceso constitucional busca proteger.

Siendo antes el proceso de amparo el medio más empleado por aquellas personas que veían conculcado(s) alguno(s) de sus derechos laborales constitucionalmente protegidos, qué duda cabe que hoy el escenario pasa a ser muy distinto, pues, como ya hemos adelantado, actualmente, antes de acudir al amparo, debiera recurrirse a los procesos ordinarios, siempre que resulten, eso sí, igualmente satisfactorios, tal como lo exige el Código Procesal Constitucional.

\section{Algunos criterios que deben considerarse para calificar a una vía especí- fica como igualmente satisfactoria ${ }^{45}$}

La determinación de una vía como igualmente satisfactoria pasa, primero, por precisar la pretensión del demandante, esto es, qué busca o espera obtener al iniciar el proceso. Una vez que se tiene clara la aspiración de la persona que interpone la demanda respecto de la decisión final de la autoridad que viene conociendo su causa, se entrará a evaluar, en función de cada caso concreto, si dicho proceso resulta idóneo, suficiente y efectivo para la pretensión. Indudablemente, no estamos ante una materia fácil y serán las circunstancias particulares que revisten y rodean al asunto en litis al momento que se exige la actuación del Estado las que contribuyan a dilucidar esta cuestión. No obstante ello, podemos señalar algunos elementos que pueden, de alguna forma, hacer menos compleja la determinación de una vía como igualmente satisfactoria.

Debe tenerse presente que el recurrir al proceso constitucional de amparo presupone el desamparo, esto es, implica que el individuo se encuentra en una situación de desprotección o indefensión, si se quiere, al no tener a mano un mecanismo procesal que atienda los requerimientos de su caso en concreto.

Así, por ejemplo, será procedente el amparo si, a pesar de tener a disposición un proceso ordinario para la tutela del derecho que se invoca como amenazado o lesionado, el seguirlo, por el tiempo que puede demandar su tramitación

44 En ese sentido, lo recogido en nuestro libro El Hábeas Corpus en el Código Procesal Constitucional. Una aproximación con especial referencia a la jurisprudencia del Tribunal Constitucional peruano. Lima: Jurista Editores, 2005, pp. 142-143.

45 Para el desarrollo de este apartado de nuestro trabajo, nos hemos servido, fundamentalmente, de lo expuesto por Néstor Pedro Sagüés en su libro Derecho Procesal Constitucional. Acción de Amparo. Op. cit., p. 165 y ss, y los alcances de la jurisprudencia de la Corte Suprema de Justicia de la nación argentina que recoge en dicha obra. 
hasta la decisión final o por otras razones en función del caso en específico, puede conducir a un agravio irreparable. El carácter inminente de un perjuicio grave e irremediable y la necesidad de otorgar una tutela urgente al (o los) derecho(s) involucrado(s) obligan, en estos casos, a acudir al amparo.

Respecto de quién debiera acreditar o probar la inexistencia de otra vía igualmente satisfactoria, pues, en estos casos, la carga de la prueba recae en el demandante, es él quien se encargará de demostrar tal situación. Ahora bien, no debería exigirse, en nuestra opinión, una prueba concluyente para tal efecto, sino prima facie. En otros términos, no es suficiente con alegar la situación de desamparo, sino que hay que acreditarla, pero esta acreditación debe darse con medios probatorios que permitan deducir que, para el caso en concreto, no existe otra vía igualmente satisfactoria, sino solo el amparo. Exigirle al demandante pruebas concluyentes en esta materia puede conducir, en muchos casos, a situaciones de indefensión o desamparo y, en buena cuenta, a la inutilización de este proceso constitucional por parte de los justiciables que legítimamente invocan su procedencia. Corresponderá, finalmente, al juez decidir objetivamente este asunto.

Por otro lado, si estamos ante una circunstancia de conocimiento público o evidente que impide calificar a una vía como igualmente satisfactoria, en nuestra modesta opinión, debiera aplicarse la exención de prueba.

En caso de que el proceso ordinario previsto para la protección del derecho que se alega como amenazado o vulnerado haya pasado a dejar de ser igualmente satisfactorio como consecuencia de la conducta del agraviado, el amparo debiera ser, en principio, declarado improcedente.

El juez que conozca de una demanda de amparo y tiene una duda razonable en torno a su procedencia por considerar que puede o no existir una vía igualmente satisfactoria para el derecho que se aduce como amenazado o lesionado, debiera, a nuestro juicio, en aplicación del principio favor processum o pro actione, admitirla, de conformidad con lo establecido en el artículo III del Título Preliminar de la ley 28237, más conocida como Código Procesal Constitucional.

Los criterios mencionados anteriormente intentan, de alguna manera, contribuir a dilucidar, ante un caso concreto, si resulta realmente procedente acudir al amparo para exigir la tutela del (o los) derecho(s) fundamental(es) que se invoca(n), en este caso de índole laboral.

\section{Las vias, en principio, específicas e igualmente satisfactorias para la tu- tela de los derechos constitucionales laborales en el Perú}

Ahora bien, en el caso de la tutela de los derechos laborales como los descritos en este texto, para determinar cuál es el proceso ordinario que debiera, 
en principio, seguirse, es menester precisar el régimen al cual se encuentra adscrito el trabajador. Así, si el trabajador está sujeto al régimen público (decreto legislativo 276), será el proceso laboral público el que le resultará aplicable, mientras que, si el trabajador se encuentra, más bien, sujeto al régimen privado (decreto legislativo 728 ), sería el proceso laboral privado. Esto sucede, en ambos casos, siempre que, e insistimos con este tema, aquellos procesos se presenten como igualmente satisfactorios.

Necesario es señalar que, actualmente, no todas las personas que laboran en el sector público están sujetas a dicho régimen; por lo tanto, existen diversos procesos en función justamente del régimen al cual se encuentra adscrita cada una de ellas. Así, por ejemplo, hay quienes laboran en el sector público, pero están sujetos al régimen privado y, por consiguiente, seguirían, en principio, el proceso laboral privado y no el público. Sin embargo, con la entrada en vigencia de la ley 28175, conocida como la Ley Marco del Empleo Público, y las demás leyes de desarrollo, la existencia de diversos procesos, en función del régimen al cual se encuentra sujeto el trabajador, sería dejada de lado; de esta manera, el proceso ordinario laboral pasaría a ser uno solo, el cual debiera, en principio, seguirse en ese caso.

\section{El carácter residual del amparo en cuestión frente a la protección con- tra el despido lesivo de derechos constitucionalmente protegidos previs- ta en el ordenamiento jurídico peruano}

Dada la importancia que reviste para el asunto del cual nos venimos ocupando, no queremos dejar pasar la oportunidad para comentar la particular situación que se presenta, a nuestro modesto parecer, en el caso peruano respecto del carácter residual que hoy se le atribuye al amparo y la debida protección contra el despido lesivo de derechos constitucionalmente protegidos.

El supremo intérprete de nuestra Constitución, en casos como el ya antes mencionado Eusebio Llanos Huayco (expediente 976-2001-AA/TC), ${ }^{46}$ ha identificado dos tipos de protección contra el despido arbitrario: una «preventiva» y otra «reparadora».

La protección "preventiva» del despido arbitrario supone que el legislador "prevea», «impida» o "evite» que un trabajador pueda ser despedido de forma arbitraria. Para tal efecto, será por medio de la ley que establecerá las causales y, una vez acreditada(s) alguna(s) de estas, el previo procedimiento disciplinario, si fuera el caso. Para el Tribunal Constitucional peruano, ello se deriva del artículo 27 de la Constitución vigente. Aquella protección

46 Sentencia de fecha 13 de marzo de 2003, publicada el 13 de mayo del mismo año. 
recibe la calificación de "preventiva», toda vez que, a su criterio, la protección adecuada que enuncia dicho precepto constitucional radica en evitar el despido arbitrario.

La protección «reparadora», por su parte, ha sido desarrollada por el legislador y establece, en algunos casos, como dijimos, la indemnización; esto significa que, de producirse un despido arbitrario, la ley busca reparar el daño al trabajador que ha visto lesionado su derecho a la estabilidad laboral mediante una compensación económica.

Sin embargo, y aquí la particularidad que se presenta en el caso peruano, al no ser una reparación patrimonial un mecanismo suficiente para paliar la violación del derecho a la estabilidad en el empleo como consecuencia de un despido lesivo de derechos constitucionalmente protegidos, el proceso de amparo se presenta, a diferencia de la indemnización, como un mecanismo procesal con efectos no precisamente resarcitorios, como ocurre con la compensación económica, sino fundamentalmente restitutorios.

Como es de conocimiento general, en principio, ${ }^{47}$ la consecuencia de declarar fundada una demanda de un proceso constitucional como el amparo es

47 Decimos en principio, pues, en la realidad, pueden presentarse diversas situaciones en torno a la interposición de una demanda de un proceso constitucional de la libertad (nos referimos al hábeas corpus, amparo, hábeas data y, mientras la Constitución lo prevea como proceso constitucional, el proceso de cumplimiento) y sus consecuencias en caso de declararse fundada.

Primero, es posible que se logre restituir el derecho amenazado o vulnerado en su totalidad, como ocurre cuando uno, por ejemplo, plantea una demanda de hábeas corpus ante la privación arbitraria de la libertad personal, en cuyo caso, de declararse fundada dicha demanda, se dispondrá la inmediata libertad del agraviado.

En segundo lugar, puede que el derecho amenazado o vulnerado pueda restituirse solo parcialmente. Un ejemplo, por demás ilustrativo al respecto, es el señalado por Alberto Borea Odría y referido al derecho de reunión. Supongamos que un partido político determinado ha planeado realizar un mitin para una fecha específica, fecha que puede ser clave para los intereses de dicho partido. Sin embargo, dicho mitin no se realizó en virtud de una actuación u omisión arbitraria de una autoridad administrativa. El proceso constitucional que se interpone como consecuencia de tal agravio es declarado fundado, pero la oportunidad precisa para que la reunión tenga lugar ya pasó, por lo que, tal vez, el realizarla tiempo después no va a generar para los agraviados el mismo efecto esperado si ella tenía lugar justamente cuando pretendían. No obstante lo injusto que puede parecer la situación, en estos casos el juez indicará que dicho mitin podrá realizarse cuando los demandantes lo consideren conveniente (BOREA ODRÍA, Alberto. Evolución de las Garantías Constitucionales. Hábeas Corpus, Amparo, Hábeas Data, Acción de Cumplimiento. Lima: Fe de Erratas, 2000, p. 52).

Por último, también puede suceder que el derecho que venía siendo amenazado o lesionado no pueda ya ser restituido, es decir, luego de interpuesta la demanda, la situación devino en irreparable. Ante estos casos, según lo previsto en el artículo 1 del Código Procesal Constitucional, el juez deberá declararla fundada y ordenarle al responsable que no vuelva a incurrir en las conductas que practicó en perjuicio del agraviado y que dieron origen a la demanda. 
reponer las cosas al estado anterior a la violación del (o los) derecho(s) constitucionalmente protegido(s). Esto último quiere decir que, aun cuando existen supuestos para los cuales el proceso ordinario en caso de culminar de forma favorable al demandante conlleva a la restitución en su puesto de trabajo, si yo busco que, ante cualquier despido que considero que vulnera uno (o algunos) de mis derecho(s) protegido(s) constitucionalmente, se me restituya en el empleo, indudablemente recurriré al amparo en lugar del proceso ordinario ${ }^{48}$ ya que solo por medio de aquel podré encontrar satisfecha mi pretensión, cosa que no ocurriría si optara por la vía ordinaria, como quiera que, en la gran mayoría de casos, la consecuencia de que en este proceso se declare fundada la demanda será una compensación económica.

Así ha tenido oportunidad de reconocerlo el propio Tribunal Constitucional peruano en el caso Eusebio Llanos Huayco (expediente 976-2001$\mathrm{AA} / \mathrm{TC})^{49}$ cuando, al referirse a los mecanismos de protección adecuada contra el despido arbitrario, señala que, si bien se cuenta con la indemnización,

[...] al lado de ella, puede establecerse un sistema o régimen de protección jurisdiccional con alcances diferentes. Es decir, que en vez de prever una eficacia resarcitoria, pueda establecerse una vía procesal de eficacia restitutoria. Es lo que sucede con el régimen de protección procesal previsto a través del proceso de amparo constitucional.

Agrega, pues, que «en el ámbito del amparo, en efecto, ese estado anterior al cual debe reponerse las cosas no es el pago de una indemnización. Es la restitución del trabajador a su centro de trabajo, del cual fue precisamente despedido arbitrariamente».

\section{Una breve recapitulación a modo de conclusión}

Como hemos visto, la nueva configuración del amparo en el Perú trae consigo importantes consecuencias en lo que a la tutela de los derechos fundamentales de índole laboral se refiere. A diferencia de lo que venía ocurriendo antes del Código Procesal Constitucional, hoy, si se considera amenazada o

48 Eso sí: siempre que no estemos ante lo que el Tribunal Constitucional ha calificado como un despido injustificado, ya que, como tuvimos oportunidad de precisarlo anteriormente, en este supuesto sería necesario actuar pruebas, lo cual no es posible en el escenario del proceso de amparo.

49 Sentencia de fecha 13 de marzo de 2003, publicada el 13 de mayo del mismo año. 
vulnerada la libertad de trabajo, el derecho al trabajo ${ }^{50}$ o el derecho a la estabilidad en el empleo (algunos de los más frecuentemente invocados en sede constitucional), deberá acudirse, en principio, a los procesos ordinarios que se tiene a disposición, siempre que estos, de conformidad con el segundo inciso del artículo cinco de la ley 28237 , se presenten como igualmente satisfactorios para la pretensión.

Siendo, como dijimos, la libertad de trabajo, el derecho al trabajo y el derecho a la estabilidad en el empleo los derechos que más usualmente son invocados por los demandantes al iniciar un proceso de amparo, se hacía también necesario precisar las dimensiones o perspectivas de protección que corresponden a cada uno de ellos, así como las conductas que pueden eventualmente amenazarlos o lesionarlos. Esperamos que estas precisiones puedan contribuir a evitar las aún recurrentes confusiones entre estos derechos que se suelen presentar en la realidad.

Ahora bien, debe tenerse presente que aquel carácter residual o subsidiario que hoy el Código Procesal Constitucional le atribuye al amparo genera en los juzgadores la responsabilidad y obligación de ser prudentes al momento de conocer un caso en concreto y no declarar improcedente sin más la demanda interpuesta por el simple hecho de que existe un proceso ordinario que puede eventualmente atender el (o los) derecho(s) invocado(s). Como hemos tratado de señalar aquí muy sucintamente, la existencia de una vía ordinaria no es suficiente para inclinarse por la improcedencia de este proceso constitucional, sino que aquella deberá resultar igualmente satisfactoria.

La determinación de una vía como igualmente satisfactoria no es tarea fácil, aunque existen ciertos criterios que, aplicados al asunto en cuestión, pueden eventualmente contribuir a su precisión. Algunos de dichos criterios los hemos tratado de desarrollar aquí.

Serán los demandantes los que tendrán que probar que no existe otra vía igualmente satisfactoria para su pretensión que el proceso de amparo. Indudablemente, estamos ante una gran responsabilidad que recae sobre los accionantes; por ello, para tal efecto, debe requerirse, según nuestro entender, no

50 Aun cuando va ser en el inciso diez del artículo 37 de la ley 28237, también conocida como el Código Procesal Constitucional, en el que vamos a encontrar recogido expresamente el derecho al trabajo como parte del ámbito de protección del proceso de amparo, ello no quiere decir que solo él sea susceptible de ser tutelado por este proceso constitucional. El inciso 25 del mismo artículo nos dice que se encuentran en la misma situación los demás derechos que la Constitución reconoce. Por consiguiente, de allí y de los tratados internacionales de derechos humanos de los cuales nuestro país es parte y de los que se deriven de la dignidad de la persona, podemos deducir una gama más amplia de derechos laborales que, si no existe otra vía igualmente satisfactoria, bien pueden ser protegidos por el amparo. 
una prueba concluyente sino prima facie. Y será el juzgador el que determinará de forma objetiva si ello efectivamente es así. De existir una duda razonable en esta materia, el juez debiera inclinarse por admitir la demanda de amparo.

Finalmente, debemos señalar que, a nuestro juicio, si se presenta un caso de despido conculcatorio de un (o algunos) derecho(s) constitucionalmente protegido(s) y el sujeto agraviado busca ser repuesto en el empleo, pero no se encuentra en ninguno de los supuestos para los cuales la legislación ha previsto dicha consecuencia en el supuesto de que la demanda sea declarada fundada en el proceso ordinario, bien podrá acudir al proceso constitucional de amparo. La compensación económica prevista para la gran mayoría de casos de despido arbitrario, si se sigue la vía ordinaria, no resulta, pues, en nuestra opinión, una medida satisfactoria, en este caso, para la pretensión del demandante, mientras que el amparo sí, ya que busca reponer las cosas al estado anterior de la violación (ser repuesto en el empleo), salvo mejor parecer. 